\title{
Extremely low levels of chloroplast genome sequence variability in Astelia pumila (Asteliaceae, Asparagales)
}

\author{
Simon Pfanzelt ${ }^{1,2}$, Dirk C Albach ${ }^{2}$, K Bernhard von Hagen ${ }^{\text {corresp. } 2}$ \\ 1 Experimental Taxonomy, Leibniz Institute of Plant Genetics and Crop Plant Research, Gatersleben/Seeland, Saxony-Anhalt, Germany \\ 2 Institute of Biology and Environmental Sciences, Carl von Ossietzky University, Oldenburg, Lower Saxony, Germany \\ Corresponding Author: K Bernhard von Hagen \\ Email address: bernhard.vonhagen@uni-oldenburg.de
}

Astelia pumila (G.Forst.) Gaudich. (Asteliaceae, Asparagales) is a major element of West Patagonian cushion peat bog vegetation. With the aim to identify appropriate chloroplast markers for the use in a phylogeographic study, the complete chloroplast genomes of five A. pumila accessions from almost the entire geographical range of the species were assembled and screened for variable positions. The chloroplast genome sequence was obtained via a mapping approach, using Eustrephus latifolius (Asparagaceae) as a reference. The chloroplast genome of $A$. pumila varies in length from 158,215 bp to $158,221 \mathrm{bp}$, containing a large single copy region of $85,981-85,983 \mathrm{bp}$, a small single copy region of 18,182-18,186 bp and two inverted repeats of 27,026 bp. Genome annotation predicted a total of 113 genes, including 30 tRNA and four rRNA genes. Sequence comparisons revealed a very low degree of intraspecific genetic variability, as only 37 variable sites (18 indels, 18 single nucleotide polymorphisms, one 3-bp mutation)-most of them autapomorphies-were found among the five assembled chloroplast genomes. A Maximum likelihood analysis, based on whole chloroplast genome sequences of several Asparagales accessions representing six of the currently recognized 14 families (sensu APG IV), confirmed the phylogenetic position of $A$. pumila. The chloroplast genome of $A$. pumila is the first to be reported for a member of the astelioid clade (14 genera with c. 215 species), a basally branching group within Asparagales. 
1 Extremely low levels of chloroplast genome sequence variability in Astelia pumila

2 (Asteliaceae, Asparagales)

3 Simon Pfanzelt ${ }^{1,2}$, Dirk C. Albach ${ }^{2}$, K. Bernhard von Hagen ${ }^{2}$

4 1Experimental Taxonomy, Leibniz Institute of Plant Genetics and Crop Plant Research,

5 Gatersleben/Seeland, Saxony-Anhalt, Germany

$6{ }^{2}$ Institute of Biology and Environmental Sciences, Carl von Ossietzky University, Oldenburg,

7 Lower Saxony, Germany

8 Corresponding Author:

$9 \quad$ K. Bernhard von Hagen ${ }^{1}$

10 Email address: bernhard.vonhagen@uni-oldenburg.de 


\section{Abstract}

Astelia pumila (G.Forst.) Gaudich. (Asteliaceae, Asparagales) is a major element of West Patagonian cushion peat bog vegetation. With the aim to identify appropriate chloroplast markers for the use in a phylogeographic study, the complete chloroplast genomes of five A. pumila accessions from almost the entire geographical range of the species were assembled and screened for variable positions. The chloroplast genome sequence was obtained via a mapping approach, using Eustrephus latifolius (Asparagaceae) as a reference. The chloroplast genome of $A$. pumila varies in length from $158,215 \mathrm{bp}$ to $158,221 \mathrm{bp}$, containing a large single copy region of $85,981-85,983 \mathrm{bp}$, a small single copy region of 18,182-18,186 bp and two inverted repeats of 27,026 bp. Genome annotation predicted a total of 113 genes, including 30 tRNA and four rRNA genes. Sequence comparisons revealed a very low degree of intraspecific genetic variability, as only 37 variable sites (18 indels, 18 single nucleotide polymorphisms, one 3-bp mutation)—most of them autapomorphies - were found among the five assembled chloroplast genomes. A Maximum likelihood analysis, based on whole chloroplast genome sequences of several Asparagales accessions representing six of the currently recognized 14 families (sensu APG IV), confirmed the phylogenetic position of $A$. pumila. The chloroplast genome of $A$. pumila is the first to be reported for a member of the astelioid clade (14 genera with c. 215 species), a basally branching group within Asparagales.

\section{Introduction}

Astelia pumila (G.Forst.) Gaudich. is a dioecious, cushion-forming perennial herb. It is one of the main constituents of so-called Magellanic moorland (Godley, 1960), which prevails in the hyperoceanic fjord and channel landscape of West and Fuegian Patagonia of southwestern South America (Schmithüsen, 1956). The species occurs from $40^{\circ} \mathrm{S}$ to Cape Horn at $56^{\circ} \mathrm{S}$, and on the Falkland Islands (Islas Malvinas). In the northern part of its range, it is found on the highest summits of the Chilean Cordillera de la Costa, which harbour isolated cushion peat bog outposts. Similar moorland enclaves occur also in the Northwest Patagonian Andes (Heusser, Heusser \& Hauser, 1992; Villagrán et al., 1998; Pfanzelt, García \& Marticorena, 2013). South of $47^{\circ} \mathrm{S}$, the zonal vegetation is composed of cool-temperate Nothofagus rainforest and cushion peat bogs, where A. pumila is very abundant (Pisano, 1983; Gajardo, 1994). East of the Andes, in the arid Patagonian steppe, it is too dry for cushion peat bog development. Astelia pumila is probably insect-pollinated, however, flower visitors have never been observed during our own fieldwork. Its yellow berries were assumed to be bird-dispersed (Skottsberg, 1905). The species is probably tetraploid $(2 \mathrm{n}=64$; Moore, 1983$)$, with flow cytometric evidence that some individuals are hexaploid (S. Pfanzelt, unpublished data).

Astelia pumila belongs to Asteliaceae, a small-sized family with three genera and 36 species from the circum-Pacific region, with most species occurring in the Southern Hemisphere (Birch, 
2015). They grow in a variety of habitats, i.e. in forests, alpine fellfields and wetlands (Bayer, Appel \& Rudall, 1998). The infrafamilial phylogenetic relationships were established by Birch, Keeley, \& Morden (2012), based on DNA sequence data from chloroplast (trnL, psbA-trnH, rps 16 and petL-psbE) and nuclear (NIA-i3) regions. Birch (2015) revised the infrageneric classification of Astelia, but the placement of sect. Micrastelia, containing only A. pumila, remained unresolved (incertae sedis).

Together with other dominant cushion peat bog plant species, Astelia pumila is being used as a study system for the reconstruction of the ice-age history of Magellanic moorland with phylogeographic methods (Pfanzelt, Albach \& von Hagen, 2017; Šarhanová et al., 2018). Previous genomic resources of $A$. pumila did not exist and our preliminary search for variable chloroplast markers did not produce satisfactory results. Consequently, the chloroplast genomes of five A. pumila individuals, sampled from almost the entire distribution range of the species, were assembled and compared, with the aim to identify phylogeographically informative chloroplast regions.

Here, the complete chloroplast genome sequence of $A$. pumila is reported and its intraspecific sequence variability assessed. Until now, there was no complete chloroplast genome sequence available of lower Asparagales, neither of Asteliaceae, nor of further astelioid genera (Boryaceae, Blanfordiaceae, Lanariaceae and Hypoxidaceae). Research on chloroplast genome evolution in Asparagales has been primarily focused on orchids (e.g. Kim \& Chase, 2017; Lin et al., 2017; Roma et al., 2018) and Asparagaceae (e.g. Steele et al., 2012; McKain et al., 2016; Floden \& Schilling, 2018). Major structural rearrangements have been documented in the chloroplast genome of parasitic and mycoheterotrophic species (e.g. Barrett et al., 2014), but in photoautotrophic members of the order, deviations from the typical land plant chloroplast genome structure are restricted to the loss of single genes (Meerow, 2010; McKain et al., 2016) and slightly shifting single copy-inverted repeat boundaries (Dong et al., 2018). Therefore, we did not expect the chloroplast genome of A. pumila to show large structural changes. However, the sequence data presented here may prove helpful to enhance our understanding of the evolutionary dynamics of the monocot plastome, through narrowing the sampling gap between orchids on the one hand and higher Asparagales on the other hand.

\section{Materials \& Methods}

\section{Sampling}

As a non-model organism, for which genomic resources did not exist previously, next-generation sequencing was used to obtain DNA sequence data of five A. pumila individuals. Accessions were obtained from almost the entire distribution range of the species, including the Falkland Islands (Islas Malvinas), except for its northernmost occurrence at Cerro Mirador $\left(40^{\circ} \mathrm{S}\right)$ of south-central Chile's Los Ríos Region. 
Illumina sequencing

Different library types were prepared: (1) a chloroplast-enriched library obtained via sorting on a BD FACSAria IIu cell sorter (using fresh leaf material; cf. Wolf et al., 2005) and subsequent whole genome amplification using the REPLI-g Mini Kit (Qiagen, Hilden, Germany), (2) whole genomic DNA libraries for shotgun-sequencing (based on silica-dried leaf material) and (3) a cDNA transcript library based on RNA extracted from fresh leaf material, using the RNeasy Mini Kit (Qiagen, Hilden, Germany). Libraries were paired-end sequenced on an Illumina HiSeq 2000 at the IPK Gatersleben (Germany), with an insert size of 400-500 bp. Information on the five sequenced $A$. pumila specimens, respective library types and collection localities is given in Table 1. Voucher specimens are deposited at the herbaria of the Universidad de Concepción, Chile (CONC), and Carl-von-Ossietzky-Universität, Oldenburg, Germany (OLD). The Chilean Corporación Nacional Forestal (18/2009) and the Falkland Islands Government (R10/2012) issued collection permits.

Assembly of the chloroplast genomes

Removal of duplicate reads, adapter clipping and quality trimming was done in CLC Genomics Workbench (versions 6.5.1-7.5.1), setting the quality threshold to a qlimit of 0.001 . To obtain a first chloroplast genome draft, the pooled quality-trimmed reads of all A. pumila individuals were mapped against Eustrephus latifolius (Asparagaceae, NCBI GenBank accession number KM233639.1) as a reference, using Geneious 8.0.5 (medium-low sensitivity and a five-time iteration; https://www.geneious.com). The resulting mapping was curated manually. Chloroplast contigs from de novo assemblies, performed in VelvetOptimizer 2.2.5. (Zerbino \& Birney, 2008), were used to cross-check for eventual mapping errors, especially of reads containing homopolymer stretches, and to fill missing regions. VelvetOptimizer hash lengths ranged from 19 to 63 and were optimized for N50 (optFuncKmer 'n50'). The chloroplast genome draft was then used itself as reference against which the reads of the individual A. pumila accessions were mapped, using Geneious 8.0.5 (five-time iteration, maximum 5\% mismatches per read). The junctions between the large single copy (LSC) and the small single copy (SSC) regions and the two inverted repeats (IRs) were additionally validated through Sanger sequencing (LSC-IR $\mathrm{B}_{\mathrm{B}}$ junction: Ap-rps19F AGACATGCGAGAAACGATAA, Ap-rps3R

TGTGCGAACCAAAAGGAA; IR ${ }_{B}-S S C$ junction: Ap-IRbSSC-F CGAGTGAATGGAAAGGAAAA, Ap-IRbSSC-R TGGGGTTGGTGTTGTAAG; SSC-IR junction: Ap-IRaSSC1F GGGGAGAAAGAAAGGAAG, Ap-IRaSSC1R

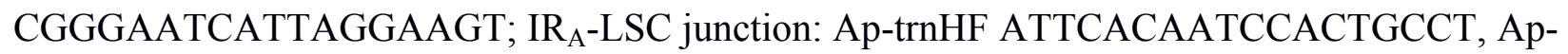
psbAR TGCTCACAACTTCCCTCT).

Genome annotation

Chloroplast genome annotation was done using DOGMA (Wyman, Jansen \& Boore, 2004; for reference chloroplast genomes, see $\mathrm{http}$ ://dogma.ccbb.utexas.edu/html/cp_taxa), and cross- 
122

123

124

125

126

127

128

129

130

131

132

133

134

135

136

137

138

139

140

141

142

143

144

145

146

147

148

149

150

151

152

153

154

155

156

157

158

checked using GeSeq (Tillich et al., 2017) and the "Annotate from ..." function in Geneious. Via that latter function, annotations can be transferred from a user-specified reference set of chloroplast genomes to the A. pumila target. The chloroplast genome of Asparagus officinalis (GenBank accession number NC_034777.1) was used as reference when employing GeSeq and Geneious for genome annotations. Where necessary, gene boundaries were corrected manually to match start and stop codons. The annotated chloroplast genome sequences were submitted to GenBank (accession numbers MH752980-MH752984). Chloroplast genome maps were drawn using OGDRAW. Both OGDRAW and GeSeq are available at the MPI-MP CHLOROBOX website (https://chlorobox.mpimp-golm.mpg.de/index.html).

Intraspecific sequence comparisons and phylogenetic reconstruction

The chloroplast genome sequences of the five A. pumila specimens (Table 1) were aligned with MAFFT (Katho et al., 2002) and screened for variable sites. Coverage cutoff was set to 100 in order to retrieve reliable markers. A NeighborNet was constructed using SplitsTree 4.14.6 (Huson \& Bryant, 2006) based on HKY85 distances. To confirm the placement of $A$. pumila within Asparagales, 22 chloroplast genome sequences, representing six of the 14 currently recognized families of the order (sensu APG IV, 2016), were downloaded from NCBI GenBank and aligned using MAFFT (Katoh et al., 2002), together with the chloroplast genome sequence of $A$. pumila individual AEX.3. There are no complete chloroplast genome sequences available yet of the remaining families of Asparagales (Boryaceae, Blandfordiaceae, Lanariaceae, Hypoxidaceae, Doryanthaceae, Ixioliriaceae, Tecophilaeaceae and Xeronemataceae). A phylogenetic tree was constructed using a Maximum Likelihood approach as implemented in RAxML 8.2.0 (Stamatakis, 2014). In a single run, a rapid bootstrap analysis and a best-scoring ML tree search were carried out, using the GTRGAMMA model of nucleotide substitution and 1000 bootstrap replicates. Alstroemeria aurea (Liliales) served as outgroup.

\section{Results}

The total lengths of the individual A. pumila chloroplast genome sequences vary from 158,215 $\mathrm{bp}$ to $158,221 \mathrm{bp}$ due to indel variation (Figure 1). The large and small single copy regions have lengths of $85,981-85,983 \mathrm{bp}$ and $18,182-18,186 \mathrm{bp}$, respectively. The inverted repeat regions have a length of $27,026 \mathrm{bp}$. GC content is $37.8 \%$. Genome annotation predicted a total of 113 genes, including 30 protein-coding genes and four rRNA genes.

Intraspecific chloroplast sequence variation was very low in A. pumila. Over a length of $158 \mathrm{~kb}$, 37 variable sites were found, of which 18 were indels, 18 single nucleotide polymorphisms (SNPs), and one a 3-bp mutation (Table 2). The latter occurred in an imperfect repetitive region and was treated as a single mutation event. All the SNPs and the 3-bp mutation were autapomorphies of which 10 occurred in non-coding regions, i.e. introns or spacers. Of the eight SNPs occurring in coding regions, four represented non-synonymous mutations. Read coverage 
159

160

161

162

163

164

165

166

167

168

169

170

171

172

173

174

175

176

177

178

179

180

181

182

183

184

185

186

187

188

189

190

191

192

193

194

195

at the SNP sites ranged from 139-2484 (mean 468, s.d. 541). The 18 observed indels had lengths of 1-2 bp. Indel variation was always associated with homopolymer runs of maximally $15 \mathrm{bp}$ length. No differences in homopolymer lengths were observed when cross-checking the Geneious mappings with the contigs of the VelvetOptimizer de novo assemblies, so indel variation was not a software-related artefact. The NeighborNet showed a star-like topology (not shown).

The phylogenetic reconstruction of Asparagales, based on whole chloroplast genome sequences, recovers Orchidaceae as basally branching within the order (Figure 2). The astelioid clade, represented in this study by Asteliaceae, is then sister to the remaining Asparagales.

\section{Discussion}

The chloroplast genome of $A$. pumila showed the typical quadripartite structure, i.e. a large and a short single copy region and two inverted repeats (Figure 1). No general differences in gene order or inversions were detected when comparing the $A$. pumila chloroplast genome to those of related Asparagales species. In general, major structural rearrangements like, for example, the IR enlargement and inversions documented for geranium (Palmer, Nugent \& Herbon, 1987) or the 22-kbp inversion that marks an early evolutionary split in Asteraceae (Jansen \& Palmer, 1987), have not been detected yet in the chloroplast genome of any Asparagales species. However, gene loss has been documented for some taxa throughout higher Asparagales (Meerow, 2010; Steele et al., 2012; McKain et al., 2016). These missing genes-clpP, ndhF, rpl32, rps 16, and rps 19are all present in the chloroplast genome of $A$. pumila. In orchids, basally branching within Asparagales, degradation of the $n d h$ gene complex has been frequently observed, especially among heterotrophic species (Neyland \& Urbatsch, 1996; Chang et al., 2006; Lin et al., 2017). By contrast, all eleven ndh genes are maintained in A. pumila. McKain et al. (2016) identified the rps 19 gene to be the most dynamic in Agavoideae (Asparagaceae). There, it was either missing, pseudogenized, or present at different positions, either within the LSC or the IR. In A. pumila, rps 19 is found within the IR, close to the LSC-IR boundaries. Located between the rps 19 and the $p s b A$ genes, there is a partial $r p l 22$ gene, truncated at the $\mathrm{LSC}_{\mathrm{SR}} \mathrm{I}$ junction. This kind of gene order was classified as Type IIIg by Wang et al. (2008), a configuration typically found in Asparagales and Commelinales. In other Asparagales, e.g. Asparagus densiflorus and Crinum asiaticum, the LSC-IR $\mathrm{IR}_{\mathrm{A}}$ junction lies downstream of the $\operatorname{rps} 19$ gene and the $\mathrm{IR}_{\mathrm{A}}$ does not include a partial $r p l 22$ gene. The structural dynamics of the LSC-IR junctions carry a phylogenetic signal, since there is an IR expansion trend in monocots: basally branching groups have generally shorter IRs than derived ones (Wang et al., 2008).

Eighteen indels of 1-2 bp length were observed among the five A. pumila accessions compared, all of which were associated with A or T homopolymer stretches of 8 to $15 \mathrm{bp}$ length. It has been shown that the indel error rate of the Illumina sequencing platforms increases after long 
196 homopolymer runs by up to two orders of magnitude (Ross et al., 2013). Therefore, indel

197 variation associated with homopolymer stretches should be treated with caution, although the 198 main sequencing errors of Illumina platforms are substitution type miscalls (Kircher, Stenzel \& 199 Kelso, 2009) with the general indel error rate being about an order of magnitude lower 200 (Laehnemann, Borkhardt \& McHardy, 2016).

201

202

203

204

205

206

207

208

209

210

211

212

213

214

215

216

217

218

219

220

221

222

223

224

225

226

227

228

229

230

231

232

233

234

Intraspecific chloroplast sequence variability was very low, although the geographical sampling covered almost the entire distribution range and included an accession from the distant Falkland Islands. The five compared chloroplast genome sequences differed only in 37 variable sites, of which 18 were indels associated with homopolymer stretches and thus of unclear reliability (see preceding paragraph). The remaining variable sites were all autapomorphies, without any phylogenetically informative content. This contrasts with previous studies on intraspecific chloroplast sequence variability in Jacobaea vulgaris (32 SNPs observed within 17 individuals, of which 11 were parsimony-informative sites; Doorduin et al., 2011) and Theobroma cacao (78 SNPs segregating within 10 individuals; Kane et al., 2012), in which genetic structuring could be observed.

Given the non-existence of genetic structuring in A. pumila, it may be speculated that West and Fuegian Patagonia, and the Falkland Islands, have been colonized only recently, probably after the last glacial. Clearly, the sampling in the present study is not adequate to allow for firm conclusions on the Pleistocene history of $A$. pumila, but such a scenario would fit to the classical biogeographic hypothesis brought forward by Villagrán $(1988 ; 2001)$, based on palynological data: Magellanic moorland species migrated northwards during the last glacial and survived in the lowlands of south-central Chile. From there, they recolonized the large Patagonian Channel region after the disintegration of the Patagonian Ice Sheet, which had reached the continental shelf south of c. $42^{\circ} \mathrm{S}$ at the height of the last glacial (Denton \& Hughes, 1981; Porter, 1981; Moreno et al., 2015). In order to properly and adequately quantify population genetic diversity and identify phylogeographic patterns in A. pumila, $>350$ individuals from almost 40 populations were genotyped at seven nuclear microsatellite loci. These data are currently being analysed and will, together with palaeodistribution modelling, shed light on the open question where A. pumila survived the glacials (Pfanzelt et al., under review).

The phylogenetic reconstruction, based on whole chloroplast genome sequences, recovered Orchidaceae as basally branching within Asparagales. Asteliaceae was then retrieved as sister to the remaining clades of the order (Figure 2). This topology is in accordance with previous multigene-based phylogenetic analyses of Asparagales (Seberg et al., 2012). The chloroplast genome of A. pumila is the first to be reported for a member of the astelioid clade of basal Asparagales. This is a major improvement in terms of published chloroplast genomes from that order, as especially orchids and subfamily Agavoideae (Asparagaceae) are very well sampled (McKain et al., 2016). Furthermore, the generated information — whole genomic DNA shotgun sequences of five A. pumila individuals and RNA-Seq data of one of them-represents a valuable genomic resource, e.g. for the identification of nuclear single copy genes. Such markers may prove useful 
235 to ascertain the still unresolved infrageneric placement of sect. Micrastelia, which contains only

236 A. pumila as its single member.

237

\section{Conclusions}

239 The comparison of whole chloroplast genome sequences of five A. pumila accessions, sampled

240 from almost the entire distribution range of the species, revealed extremely low levels of

241 sequence variability. The genomic resources generated in the course of the present study may

242 prove useful for future work on Astelia, e.g. for the development of single-copy nuclear markers.

243 These could be employed to ascertain the yet unresolved phylogenetic placement of $A$. pumila

244 within the genus.

\section{Acknowledgements}

247 The authors acknowledge the help of J. Fuchs, P. Šarhanová and M. C. García Lino. Centro 248 EULA (University of Concepción, Chile) provided logistic support. Andrew Stanworth and A. 249 Davey provided samples from the Falkland Islands (Islas Malvinas). The comments of three 250 anonymous reviewers helped to improve a previous version of the manuscript.

251

\section{References}

253

254

255

256

257

258

259

260

261

262

263

264

265

266

APG IV. 2016. An update of the Angiosperm Phylogeny Group classification for the orders and families of flowering plants: APG IV. Botanical Journal of the Linnean Society 181, 1-20 DOI: 10.1111/boj.12385.

Barrett CF, Freudenstein JV, Li J, Mayfield-Jones DR, Perez L, Pires JC, Santos C. 2014. Investigating the path of plastid genome degradation in an early-transitional clade of heterotrophic orchids, and implications for heterotrophic angiosperms. Molecular Biology and Evolution 31(12): 3095-3112 DOI:10.1093/molbev/msu252.

Bayer C, Appel O, Rudall PJ. 1998. Asteliaceae. In: Kubitzki K, Huber H., eds. Flowering plants, monocotyledons: Lilianae (except Orchidaceae). Berlin, Springer, 141-145.

Birch JL. 2015. A revision of infrageneric classification in Astelia Banks \& Sol. ex R.Br. (Asteliaceae). PhytoKeys 52: 105-132 DOI: 10.3897/phytokeys.52.4768.

Birch JL, Keeley SC, Morden CW. 2012. Molecular phylogeny and dating of Asteliaceae (Asparagales): Astelia s.l. evolution provides insight into the Oligocene history of New Zealand. Molecular Phylogenetics and Evolution 65: 102-115 DOI: 10.1016/j.ympev.2012.05.031. 
267 Chang CC, Lin HC, Lin IP, Chow TY, Chen HH, Chen WH, Cheng CH, Lin CY, Liu SH, Chang 268 CC, Chaw SM. 2006. The chloroplast genome of Phalaenopsis aphrodite (Orchidaceae): 269 comparative analysis of evolutionary rate with that of grasses and its phylogenetic implications.

270 Molecular Biology and Evolution 23: 279-291 DOI:10.1093/molbev/msj029.

271 Denton GH, Hughes TJ. 1981. The Last Great Ice Sheets. New York: Wiley-Interscience.

272 Dong W-L, Wang R-N, Zhang N-Y, Fan W-B, Fang M-F, Li Z-H. 2018. Molecular Evolution of 273 chloroplast genomes of orchid species: insights into phylogenetic relationships and adaptive 274 evolution. International Journal of Molecular Sciences 19(3): 716 DOI: 10.3390/ijms 19030716.

275 Doorduin L, Gravendeel B, Lammers Y, Ariyurek Y, Chin-A-Woeng T, Vrieling K. 2011. The 276 complete chloroplast genome of 17 individuals of pest species Jacobaea vulgaris: SNPs, 277 microsatellites and barcoding markers for population and phylogenetic studies. DNA Research 278 18: 93-105 DOI:10.1093/dnares/dsr002.

279 Floden A, Schilling EE. 2018. Using phylogenomics to reconstruct phylogenetic relationships 280 within tribe Polygonateae (Asparagaceae), with a special focus on Polygonatum. Molecular 281 Phylogenetics and Evolution 129: 202-213 DOI 10.1016/j.ympev.2018.08.017.

282 Gajardo R. 1994. La vegetación natural de Chile: Clasificación y distribución geográfica. 283 Santiago de Chile: Editorial Universitaria.

284 Godley EJ. 1960. The botany of southern Chile in relation to New Zealand and the Subantarctic. 285 Proceedings of the Royal Society of London. Series B, Biological Sciences 152: 457-475.

286 Heusser CJ, Heusser LE, Hauser A. 1992. Paleoecology of Late Quaternary deposits in Chiloé 287 Continental, Chile. Revista Chilena de Historia Natural 65: 235-245.

288 Huson DH, Bryant D. 2006. Application of phylogenetic networks in evolutionary studies. 289 Molecular Biology and Evolution 23: 254-267 DOI: 10.1093/molbev/msj030.

290 Jansen RK, Palmer JD. 1987. A chloroplast DNA inversion marks an ancient evolutionary split 291 in the sunflower family (Asteraceae). Proceedings of the National Academy of Sciences USA 292 84(16): 5818-5822 DOI: 10.1073/pnas.84.16.5818.

293 Kane N, Sveinsson S, Dempewolf H, Yang JY, Zhang D, Engels JMM, Cronk Q. 2012. Ultra294 barcoding in cacao (Theobroma spp.; Malvaceae) using whole chloroplast genomes and nuclear 295 ribosomal DNA. American Journal of Botany 99: 320-329 DOI:10.3732/ajb.1100570.

296 Katoh K, Misawa K, Kuma K, Miyata T. 2002. MAFFT: a novel method for rapid multiple 297 sequence alignment based on fast Fourier transform. Nucleic Acids Research 30: 3059-3066 298 DOI: 10.1093/nar/gkf436. 
299

300

301

302

303

304

305

306

307

308

309

310

311

312

313

314

315

316

317

318

319

320

321

322

323

324

325

326

327

328

329

330

331

332

Kim HT, Chase MW. 2017. Independent degradation in genes of the plastid ndh gene family in species of the orchid genus Cymbidium (Orchidaceae; Epidendroideae). PLoS ONE 12(11): e0187318 DOI: 10.1371/journal.pone.0187318.

Kircher M, Stenzel U, Kelso J. 2009. Improved base calling for the Illumina Genome Analyzer using learning strategies. Genome Biology 10: R83 DOI: 10.1186/gb-2009-10-8-r83.

Laehnemann D, Borkhardt A, McHardy AC. 2016. Denoising DNA deep sequencing datahigh-throughput sequencing errors and their correction. Briefings in Bioinformatics 17: 154-179 DOI: $10.1093 / \mathrm{bib} / \mathrm{bbv} 029$.

Lin CS, Chen JJW, Chiu C-C, Hsiao HCW, Yang C-J, Jin X-H, Leebens-Mack J, de Pamphilis CW, Huang Y-T, Yang L-H, Chang W-J, Kui L, Wong GK-S, Hu J-M, Wang W, Shih M-C. 2017. Concomitant loss of NDH complex-related genes within chloroplast and nuclear genomes in some orchids. The Plant Journal 90: 994-1006 DOI: 10.1111/tpj.13525.

McKain MR, McNeal JR, Kellar PR, Eguiarte LE, Pires, JC, Leebens-Mack J. 2016. Timing of rapid diversification and convergent origins of active pollination within Agavoideae. American Journal of Botany 103: 1717-1729 DOI:10.3732/ajb.1600198.

Meerow AW. 2010. Convergence or reticulation? Mosaic evolution in the canalized American Amaryllidaceae. In: Seberg O, Petersen G, Barfod AS, Davis JI, eds. Diversity, phylogeny and evolution in the monocotyledons. Aarhus, Aarhus University Press, 145-168.

Moore DM. 1983. Flora of Tierra del Fuego. Ostwestry, Anthony Nelson.

Moreno PI, Denton GH, Moreno H, Lowell TV, Putnam AE, Kaplan MR. 2015. Radiocarbon chronology of the last glacial maximum and its termination in northwestern Patagonia. Quaternary Science Reviews 122: 233-249 DOI: 10.1016/j.quascirev.2015.05.027.

Neyland R, Urbatsch LE. 1996. Phylogeny of subfamily Epidendroideae (Orchidaceae) inferred from $n d h F$ chloroplast gene sequences. American Journal of Botany 83: 1195-1206 DOI: 10.1002/j.1537-2197.1996.tb13901.x.

Palmer JD, Nugent JM, Herbon LA. 1987. Unusual structure of geranium chloroplast DNA: A triple-sized inverted repeat, extensive gene duplications, multiple inversions, and two repeat families. Proceedings of the National Academy of Sciences USA 84(3): 769-773 DOI: 10.1073/pnas.84.3.769.

Pfanzelt S, García C, Marticorena A. 2013. Notes on the Chilean geographic distribution of several vascular plant species. Check List 9, 832-837 DOI: 10.15560/9.4.832.

Pfanzelt S, Albach DC, von Hagen KB. 2017. Tabula rasa in the Patagonian Channels? The phylogeography of Oreobolus obtusangulus (Cyperaceae). Molecular Ecology 26: 4027-4044 DOI: $10.1111 / \mathrm{mec} .14156$. 
333 Pisano E. 1983. The Magellanic tundra complex. In: Gore A, ed. Ecosystems of the world,

334 Volume 4B, Mires: swamp, bog, fen and moor. Amsterdam, Elsevier Science, 295-329.

335 Porter SC. 1981. Pleistocene glaciation in the Southern Lake District of Chile. Quaternary

336 Research 16: 263-292.

337 Roma L, Cozzolino S, Schlüter PM, Scopece G, Cafasso D. 2018. The complete plastid genomes

338 of Ophrys iricolor and O. sphegodes (Orchidaceae) and comparative analyses with other orchids.

339 PLoS ONE 13(9): e0204174 DOI: 10.1371/journal.pone.0204174.

340 Ross MG, Russ C, Costello M, Hollinger A, Lennon NJ, Hegarty R, Nusbaum C, Jaffe DB.

341 2013. Characterizing and measuring bias in sequence data. Genome Biology 14: R51 DOI:

342 10.1186/gb-2013-14-5-r51.

343 Šarhanová P, Pfanzelt S, Brandt R, Himmelbach A, Blattner FR. 2018. SSR-seq: Genotyping of

344 microsatellites using next-generation sequencing reveals higher level of polymorphism as

345 compared to traditional fragment size scoring. Ecology and Evolution 8: 10817-10833 DOI:

$346 \quad 10.1002 /$ ece 3.4533.

347 Schmithüsen J. 1956. Die räumliche Ordnung der chilenischen Vegetation. Bonner

348 Geographische Abhandlungen 17: 1-86.

349 Seberg O, Petersen G, Davis JI, Pires CJ, Stevenson DW, Chase MW, Fay MM, Devey DS,

350 Jørgensen T, Sytsma KJ, Pillon Y. 2012. Phylogeny of the Asparagales based on three plastid

351 and two mitochondrial genes. American Journal of Botany 99: 875-899

352 DOI:10.3732/ajb.1600198.

353 Skottsberg C. 1905. Feuerländische Blüten. Wissenschaftliche Ergebnisse der Schwedischen

354 Süd-Polarexpedition 1901-1903, Band 4, Lieferung 2. Stockholm, Lithographisches Institut des

355 Generalstabs.

356 Stamatakis A. 2014. RAxML Version 8: A tool for phylogenetic analysis and post-analysis of

357 large phylogenies. Bioinformatics 30: 1312-1313 DOI: 10.1093/bioinformatics/btu033.

358 Steele PR, Hertweck KL, Mayfield D, McKain MR, Leebens-Mack J, Pires JC. 2012. Quality

359 and quantity of data recovered from massively parallel sequencing: examples in Asparagales and

360 Poaceae. American Journal of Botany 99: 330-348 DOI:10.3732/ajb.1100491.

361 Tillich M, Lehwark P, Pellizzer T, Ulbricht-Jones ES, Fischer A, Bock R, Greiner S. 2017.

362 GeSeq - versatile and accurate annotation of organelle genomes. Nucleic Acids Research 45:

363 W6-W11 DOI: 10.1093/nar/gkx391.

364 Villagrán, C. 1988. Expansion of Magellanic moorland during the late Pleistocene: palynological

365 evidence from northern Isla de Chilóe, Chile. Quaternary Research 30: 304-314 DOI:

366 10.1016/0033-5894(88)90006-3. 
367 Villagrán, C. 2001. Un modelo de la historia de la vegetación de la Cordillera de La Costa de 368 Chile central-sur: la hipótesis glacial de Darwin. Revista Chilena de Historia Natural 74: 793369803.

370 Villagrán C, Le-Quesne C, Aravena JC, Jiménez H, Hinojosa F. 1998. El rol de los cambios de 371 clima del cuaternario en la distribución actual de la vegetación de Chile central-sur. Bamberger 372 Geographische Schriften 15: 227-242.

373 Wang RJ, Cheng CL, Chang CC, Wu CL, Su TM, Chaw SM. 2008. Dynamics and evolution of 374 the inverted repeat-large single copy junctions in the chloroplast genomes of monocots. $B M C$ 375 Evolutionary Biology 8: 36 DOI: 10.1186/1471-2148-8-36.

376 Wolf PG, Karol KG, Mandoli DF, Kuehl J, Arumuganathan K, Ellis MW, Mishler BD, Kelch 377 DG, Olmstead RG, Boore JL. 2005. The first complete chloroplast genome sequence of a 378 lycophyte, Huperzia lucidula (Lycopodiaceae). Gene 350: 117-128 DOI:

379 10.1016/j.gene.2005.01.018.

380 Wyman SK, Jansen RK, Boore JL. 2004. Automatic annotation of organellar genomes with 381 DOGMA. Bioinformatics 20: 3252-3255 DOI: 10.1093/bioinformatics/bth352.

382 Zerbino DR, Birney E. 2008. Velvet: algorithms for de novo short read assembly using de Bruijn 383 graphs. Genome Research 18: 821-829 DOI: 10.1101/gr.074492.107. 
384 Figure 1 The chloroplast genome map of Astelia pumila specimen AEX.3 (see Table 1). Genes 385 shown on the outside of the outer circle are transcribed clockwise, while genes shown on the 386 inside are transcribed counterclockwise. The positions of the large (LSC) and small single copy 387 (SSC) regions, as well as of the inverted repeats (IRs) are indicated on the inner circle.

388 Figure 2 Maximum Likelihood tree, based on whole chloroplast genome sequences, to illustrate 389 the phylogenetic position of A. pumila within Asparagales. Alstroemeria aurea (Liliales, 390 Alstroemericeae) served as outgroup. Numbers indicate node support (based on 1000 bootstrap 391 replicates). NCBI GenBank accession numbers: A. aurea, KC968976; V planifolia, KJ566306; 392 D. nobile, KX377961; C. aloifolium, NC_021429; A. pumila, MH752983; I. gatesii, 393 NC_024936; A. maculata, KX377523; A. coddii, KX790363; A. prattii, MG739457; A. cepa, 394 NC_024813; E. latifolius, NC_025305; A. officinalis, KY364194; N. atopocarpa, KX931462; M. 395 bicolor, NC_035970; P. sibiricum, KT695605; P. verticillatum, KT722981; A. monspeliensis, 396 KX790360; H. parviflora, NC_032703; Y. brevifolia, NC_032711; M. biflora, KX822778; $O$. 397 biflora, NC_032709; B. japonica, KX822775; A. kirkii, NC_032697. 


\section{Table $\mathbf{1}$ (on next page)}

Information on the sequenced $A$. pumila specimens, respective DNA library types and collection localities. 
Information on the sequenced $A$. pumila specimens, respective DNA library types and collection localities.

\begin{tabular}{|c|c|c|c|c|c|}
\hline Accession & Library type & Voucher & Collection locality & $\begin{array}{l}\text { Geographic } \\
\text { coordinates }\end{array}$ & $\begin{array}{l}\text { GenBank } \\
\text { accession } \\
\text { number }\end{array}$ \\
\hline ACM0. 8 & whole gDNA & $\begin{array}{l}\text { Pfanzelt } 756 \text { (CONC } \\
\text { 180089) }\end{array}$ & $\begin{array}{l}\text { Chile, Los Lagos, Villa Santa } \\
\text { Lucía, Cuesta Moraga }\end{array}$ & $\begin{array}{l}43.326^{\circ} \mathrm{S} \\
72.390^{\circ} \mathrm{W}\end{array}$ & MH752984 \\
\hline AEX. 3 & whole gDNA & Pfanzelt 477 (OLD) & $\begin{array}{l}\text { Chile, Magallanes, Estero } \\
\text { Excelsior }\end{array}$ & $\begin{array}{l}52.554^{\circ} \mathrm{S} \\
72.877^{\circ} \mathrm{W}\end{array}$ & MH752983 \\
\hline AFLK. 3 & whole gDNA & $\begin{array}{l}\text { Stanworth \& Davey } \\
\text { S.n. (OLD) }\end{array}$ & $\begin{array}{l}\text { Falkland Islands, East } \\
\text { Falkland }\end{array}$ & $\begin{array}{l}51.680^{\circ} \mathrm{S} \\
57.937^{\circ} \mathrm{W}\end{array}$ & MH752980 \\
\hline ALM & $\begin{array}{l}\text { cp-enriched, } \\
\text { cDNA }\end{array}$ & Pfanzelt 903 (OLD) & $\begin{array}{l}\text { Chile, Los Lagos, Cordillera } \\
\text { Sarao }\end{array}$ & $\begin{array}{l}40.954^{\circ} \mathrm{S} \\
73.731^{\circ} \mathrm{W}\end{array}$ & MH752981 \\
\hline AQU8. 1 & whole gDNA & $\begin{array}{l}\text { Pfanzelt \& García } \\
\text { Lino } 535 \text { (OLD) }\end{array}$ & Chile, Aysén, Queulat & $\begin{array}{l}44.601^{\circ} \mathrm{S} \\
72.439^{\circ} \mathrm{W}\end{array}$ & MH752982 \\
\hline
\end{tabular}




\section{Table 2 (on next page)}

Variable positions among five compared whole chloroplast genome sequences of Astelia pumila.

Indel variation was exclusively associated with homopolymer stretches, of which length and identity of the repeat unit are given. Amino acid codes: F, phenylanaline; L, leucine; R, arginine; S, serine; $\mathrm{Y}$, tyrosine. N. a., not applicable. 
Variable positions among five compared whole chloroplast genome sequences of Astelia pumila.

Indel variation was exclusively associated with homopolymer stretches, of which length and identity of the repeat unit are given. Amino acid codes: F, phenylanaline; L, leucine; R, arginine; S, serine; Y, tyrosine. N. a., not applicable.

\begin{tabular}{|c|c|c|c|c|c|c|c|c|}
\hline Position & Region & Type & ACMO .8 & AEX. 3 & AFLK. 3 & ALM & AQU8. 1 & SNP category \\
\hline 73432 & clpP intron 1 & $3 \mathrm{bp}$ & AAA & AAA & AAA & AAA & TTT & n. a. \\
\hline 9356 & $\begin{array}{c}t r n S-G C U-t r n S-C G A \\
\text { spacer }\end{array}$ & indel & $13 \mathrm{~A}$ & $15 \mathrm{~A}$ & $13 \mathrm{~A}$ & $13 \mathrm{~A}$ & $13 \mathrm{~A}$ & n. a. \\
\hline 14799 & atpI-atpH spacer & indel & $12 \mathrm{~T}$ & $11 \mathrm{~T}$ & $12 \mathrm{~T}$ & $12 \mathrm{~T}$ & $12 \mathrm{~T}$ & n. a. \\
\hline 23333 & rpoC1 intron & indel & $10 \mathrm{~T}$ & $11 \mathrm{~T}$ & $10 \mathrm{~T}$ & $10 \mathrm{~T}$ & $10 \mathrm{~T}$ & n. a. \\
\hline 29135 & $\begin{array}{c}\operatorname{trnC}-G C A-\text { petN } \\
\text { spacer }\end{array}$ & indel & $10 \mathrm{~A}$ & $9 \mathrm{~A}$ & $10 \mathrm{~A}$ & $10 \mathrm{~A}$ & $10 \mathrm{~A}$ & n. a. \\
\hline 37554 & $\begin{array}{l}\text { psbZ-trnG-UCC } \\
\text { spacer }\end{array}$ & indel & $11 \mathrm{~A}$ & $11 \mathrm{~A}$ & $11 \mathrm{~A}$ & $10 \mathrm{~A}$ & $11 \mathrm{~A}$ & n. a. \\
\hline 46595 & $\begin{array}{c}\text { trnS-GGA-rps4 } \\
\text { spacer }\end{array}$ & indel & $10 \mathrm{~A}$ & $10 \mathrm{~A}$ & $11 \mathrm{~A}$ & $10 \mathrm{~A}$ & $10 \mathrm{~A}$ & n. a. \\
\hline 48875 & trnL-UAA intron & indel & $8 \mathrm{~A}$ & $8 \mathrm{~A}$ & $9 \mathrm{~A}$ & $8 \mathrm{~A}$ & $8 \mathrm{~A}$ & n. a. \\
\hline 49336 & $\begin{array}{c}\operatorname{trnL}-U A A-t r n F-G A A \\
\text { spacer }\end{array}$ & indel & $12 \mathrm{~T}$ & $12 \mathrm{~T}$ & $12 \mathrm{~T}$ & $12 \mathrm{~T}$ & $13 \mathrm{~T}$ & n. a. \\
\hline 57002 & $a t p B-r b c L$ & indel & $13 \mathrm{~T}$ & $13 \mathrm{~T}$ & $13 \mathrm{~T}$ & $13 \mathrm{~T}$ & $14 \mathrm{~T}$ & n. a. \\
\hline 72632 & clpP intron 2 & indel & $12 \mathrm{~T}$ & $13 \mathrm{~T}$ & $12 \mathrm{~T}$ & $12 \mathrm{~T}$ & $12 \mathrm{~T}$ & n. a. \\
\hline 73328 & clpP intron 1 & indel & $12 \mathrm{~T}$ & $12 \mathrm{~T}$ & $10 \mathrm{~T}$ & $13 \mathrm{~T}$ & $13 \mathrm{~T}$ & n. a. \\
\hline 73666 & clpP intron 1 & indel & $13 \mathrm{~T}$ & $11 \mathrm{~T}$ & $12 \mathrm{~T}$ & $12 \mathrm{~T}$ & $12 \mathrm{~T}$ & n. a. \\
\hline 83264 & rpl14-rpl16 & indel & $13 \mathrm{~T}$ & $11 \mathrm{~T}$ & $11 \mathrm{~T}$ & $12 \mathrm{~T}$ & $11 \mathrm{~T}$ & n. a. \\
\hline 84702 & rpl16 intron & indel & $14 \mathrm{~T}$ & $14 \mathrm{~T}$ & $15 \mathrm{~T}$ & $14 \mathrm{~T}$ & $14 \mathrm{~T}$ & n. a. \\
\hline 115430 & ndhF-rpl32 spacer & indel & $10 \mathrm{~A}$ & $9 \mathrm{~A}$ & $10 \mathrm{~A}$ & $10 \mathrm{~A}$ & $10 \mathrm{~A}$ & n. a. \\
\hline 116569 & $\begin{array}{c}\text { rpl32-trnL-UAG } \\
\text { spacer }\end{array}$ & indel & $13 \mathrm{~T}$ & $11 \mathrm{~T}$ & $13 \mathrm{~T}$ & $12 \mathrm{~T}$ & $12 \mathrm{~T}$ & n. a. \\
\hline 116734 & $\begin{array}{c}\text { rpl32-trnL-UAG } \\
\text { spacer }\end{array}$ & indel & $14 \mathrm{~T}$ & $13 \mathrm{~T}$ & $13 \mathrm{~T}$ & $13 \mathrm{~T}$ & $13 \mathrm{~T}$ & n. a. \\
\hline 121696 & ndhG-ndhI spacer & indel & $10 \mathrm{~T}$ & $10 \mathrm{~T}$ & $11 \mathrm{~T}$ & $10 \mathrm{~T}$ & $10 \mathrm{~T}$ & n. a. \\
\hline 1662 & trnK-UUU intron & SNP & C & C & $\mathrm{C}$ & $\mathrm{C}$ & A & n. a. \\
\hline 2873 & matK CDS & SNP & G & G & G & $\mathrm{T}$ & G & $\underset{S \rightarrow Y}{\text { non-synonymous }}$ \\
\hline 16456 & rps2 CDS & SNP & G & G & G & A & G & synonymous \\
\hline 18775 & rpoc2 CDS & SNP & C & A & C & C & $\mathrm{C}$ & $\underset{L \rightarrow F}{\text { non-synonymous }}$ \\
\hline 31960 & $\begin{array}{c}\operatorname{trnD}-G U C-t r n Y-G U A \\
\text { spacer }\end{array}$ & SNP & $\mathrm{T}$ & C & $\mathrm{C}$ & $\mathrm{C}$ & C & n. a. \\
\hline 41582 & psaA CDS & SNP & $\mathrm{T}$ & C & $\mathrm{T}$ & $\mathrm{T}$ & $\mathrm{T}$ & synonymous \\
\hline 43551 & psaA-ycf3 spacer & SNP & C & $\mathrm{T}$ & C & C & C & n. a. \\
\hline 50166 & 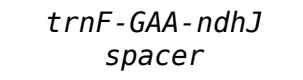 & SNP & G & G & G & G & $\mathrm{T}$ & n. a. \\
\hline 54434 & $\operatorname{trnC}-A C A$ intron & SNP & G & A & G & G & G & n. a. \\
\hline 64527 & petA CDS & SNP & $\mathrm{T}$ & C & $\mathrm{T}$ & $\mathrm{T}$ & $\mathrm{T}$ & synonymous \\
\hline 69323 & psaJ-rpl33 & SNP & A & A & A & C & A & n. a. \\
\hline
\end{tabular}




\begin{tabular}{|c|c|c|c|c|c|c|c|c|}
\hline 78402 & petB exon 2 & SNP & G & G & G & A & G & synonymous \\
\hline 80834 & rpoA CDS & SNP & $\mathrm{T}$ & $\mathrm{T}$ & $\mathrm{T}$ & $\mathrm{T}$ & G & $\underset{L \rightarrow F}{\text { non-synonymous }}$ \\
\hline 113101 & $\begin{array}{l}\text { trnN-GUU-ndhF } \\
\text { spacer }\end{array}$ & SNP & A & A & $\mathrm{T}$ & A & A & n. a. \\
\hline 116443 & $\begin{array}{l}\text { rpl32-trnL-UAG } \\
\text { spacer }\end{array}$ & SNP & C & C & C & A & C & n. a. \\
\hline 116625 & $\begin{array}{c}r p l 32-t r n L-U A G \\
\text { spacer }\end{array}$ & SNP & G & G & G & G & $\mathrm{T}$ & n. a. \\
\hline 118257 & ccsA-ndhD spacer & SNP & $\mathrm{T}$ & A & $\mathrm{T}$ & $\mathrm{T}$ & $\mathrm{T}$ & n. a. \\
\hline 127013 & $y c f 1 C D S$ & SNP & C & A & c & C & C & $\begin{array}{c}\text { non- synonymous } \\
R \rightarrow L\end{array}$ \\
\hline
\end{tabular}


Figure $\mathbf{1}$ (on next page)

The chloroplast genome map of Astelia pumila specimen AEX.3 (see Table 1).

Genes shown on the outside of the outer circle are transcribed clockwise, while genes shown on the inside are transcribed counterclockwise. The positions of the large (LSC) and small single copy (SSC) regions, as well as of the inverted repeats (IRs) are indicated on the inner circle. 


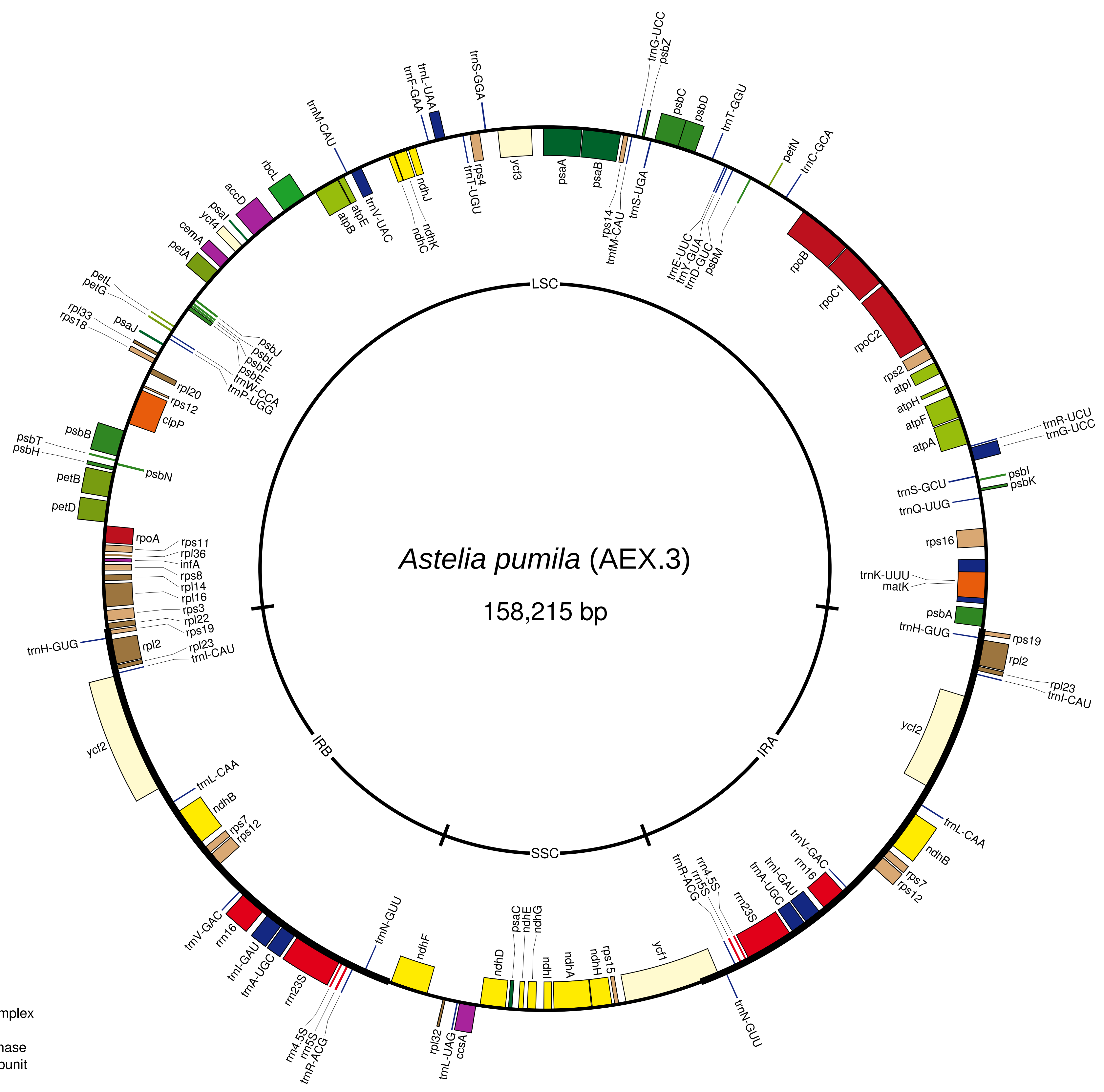

$\square$ ribosomal proteins (SSU) 


\section{Figure 2 (on next page)}

Maximum Likelihood tree, based on whole chloroplast genome sequences, to illustrate the phylogenetic position of $A$. pumila within Asparagales.

Alstroemeria aurea (Liliales, Alstroemericeae) served as outgroup. Numbers indicate node support (based on 1000 bootstrap replicates). NCBI GenBank accession numbers: $A$. aurea, KC968976; V. planifolia, KJ566306; D. nobile, KX377961; C. aloifolium, NC_021429; A. pumila, MH752983; I. gatesii, NC_024936; A. maculata, KX377523; A. coddii, KX790363; A. prattii, MG739457; A. cepa, NC_024813; E. latifolius, NC_025305; A. officinalis, KY364194; N. atopocarpa, KX931462; M. bicolor, NC_035970; P. sibiricum, KT695605; P. verticillatum, KT722981; A. monspeliensis, KX790360; H. parviflora, NC_032703; Y. brevifolia, NC_032711; M. biflora, KX822778; O. biflora, NC_032709; B. japonica, KX822775; A. kirkii, NC_032697. 


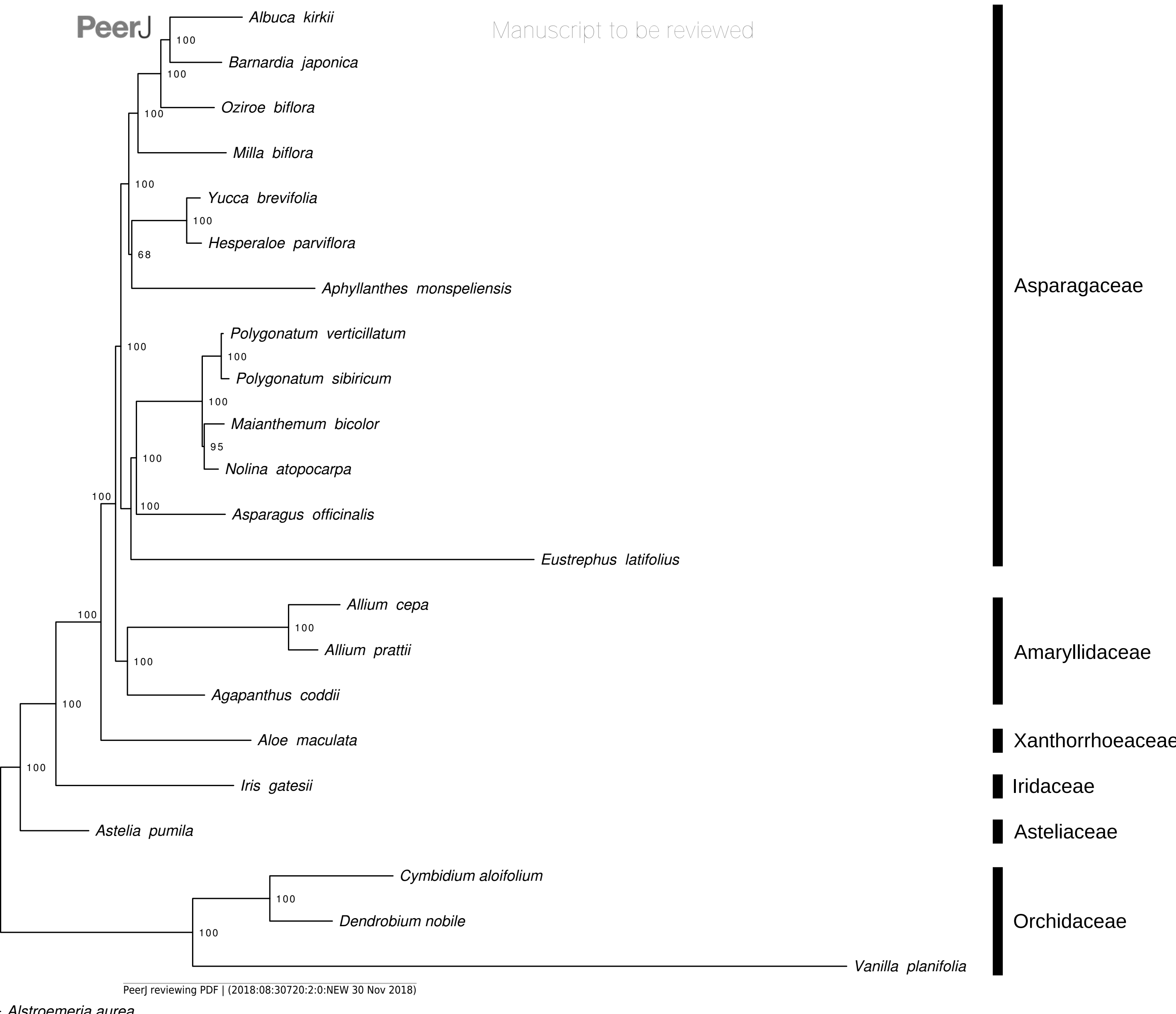

